\title{
Effect of light intensities on the photosynthetic characteristics of Abies holophylla seedlings from different provenances
}

\author{
Z. Yao, C. Xu, Y. Chai, H. Wei
}

Yao Z., Xu C., Chai Y., Wei H., 2014. Effect of light intensities on the photosynthetic characteristics of Abies holophylla seedlings from different provenances. Ann. For. Res. 57(2): 181-196, 2014.

Abstract. The photosynthetic characteristics of Abies holophylla seedlings from six provenances under four artificial light intensities in a greenhouse (full light, $75.08 \%, 55.42 \%$, and $30.38 \%$ of full light) were studied to explore the underlying genetic differences in foliar photosynthesis. Varying light intensities significantly affected the foliar photosynthetic parameters of $A$. holophylla seedlings from six provenances. As the light intensity dropped, the foliar $\mathrm{CO}_{2}$ assimilation capacity of A. holophylla seedlings sharply decreased, and the foliar light utilization capacity significantly increased. Analysis of genetic variation showed highly significant differences in terms of $\mathrm{CO}_{2}$ assimilation capacity, light utilization capacity, and respiration depletion of $A$. holophylla seedlings among different provenances under different light intensities. The variations were mainly controlled by the genetic factors of the provenance itself. The obtained results revealed that different sensitivities of $A$. holophylla seedlings from different provenances in response to changed light intensities elicited significant differences in foliar photosynthesis among different provenances. The relationships between sensitivities and annual temperature difference, mean temperature in January, and mean annual evaporation of provenance were found to be the most closely related, which indicated that temperature range and effective precipitation of provenance were the main factors that affected photosynthetic plasticity of A. holophylla seedlings. Keywords Abies holophylla seedling, provenance, light intensity, genetic difference, photosynthetic characteristics.

Authors. Zhengmao Yao, Chengyang Xu (chyxubjfu@gmail.com), Yuan Chai Key Laboratory for Silviculture and Conservation of Ministry of Education, Beijing Forestry University, No.35 Tsinghua East Road, Beijing 100083, China; Hongxu Wei - Research Group of Urban Forests and Wetlands, Key Laboratory of Wetland Ecology \& Environment, Northeast Institute of Geography and Agroecology, Chinese Academy of Sciences, No.4888 Shengbei Street, Changchun 130102, Jilin, China.

Manuscript received August 08, 2014; revised October 31, 2014; accepted November 05, 2014; online first November 15, 2014. 


\section{Introduction}

Light is one of the foremost environmental factors that affect survival, growth, and regeneration of trees. The need for light and the characteristics of the response and adaptation to different light environments vary among different tree species and different developmental stages for a given tree species (Wyka et al. 2012). The seedling stage is the period when trees are the most vulnerable and the most sensitive to environmental stress throughout the whole life cycle (Pérez-Ramos et al. 2010, Castanha et al. 2013). Light is a crucial factor that influences early survival and growth of tree seedlings growing under forest canopies (Wang et al. 2006). As a result, tree seedlings have evolved to adapt to a certain light environment by modifying their morphological and physiological plasticity (Carne 2013), which are important countermeasures for the survival, growth, and reproduction of trees in a changing environment.

Through natural selection and adaptation, the kindred tree seedlings, which grow under a certain environmental condition, will mutate to share the same or similar morphological and physiological characteristics, eventually resulting in a specific geographic population (Chong et al. 2013, Babaei et al. 2014). Light availability is an important factor controlling phenotypic plasticity (Rodríguez-García \& Bravo 2013). Photosynthetic ability in a seedling is affected by the combination of both endogenous genetic characteristics and exogenous environment and climate influences (Reinhardt et al. 2011) and inevitably mutate among different provenances (Goldblum et al. 2012, Nasr et al. 2013). Therefore, variation in photosynthetic characteristics is a major trait that depends on the different provenances (Okuto \& Ouma 2010, Sunil et al. 2013). Variation in foliar photosynthesis among different genotypes is related to the presence of different degrees of genetic variation reflecting gas exchange capabilities (Aspinwall et al. 2011).
Inherent genetic physiological difference is one of the main causes that results in differences in the variation modes of photosynthetic characteristics (Andrews et al. 2012, Soustani et al. 2014). Photosynthetic plasticity greatly improves the resistance and the ability to obtain resources of an individual tree seedling ( $\mathrm{e}$ Silva et al. 2012) and also improves the competitive ability in the environment (Paquette et al. 2012), thereby laying a solid foundation for the survival and reproduction. Therefore, studying the photosynthetic characteristics of different trees is an effective way to understand the survival mechanisms of adaptation to the light environment (Klein et al. 2013, Flexas et al. 2014). However, the extent of environmental influence and genetic influence of photosynthesis in different genotypes of plants should be studied. The changes in photosynthetic characteristics in response to light gradients among different genotype groups are also an important aspect to be studied. At present, only a few studies focused on the above mentioned questions.

Abies holophylla, a typical species of the genus Abies, is one of the main timber species that exists in temperate coniferous and broadleaved mixed forest during late succession in Northeast China. A. holophylla generationally coexists with other species to form multi-tier and uneven aged stand in natural forests. Most natural communities of $A$. holophylla have a scattered distribution with little clumps in the forest. The regeneration of $A$. holophylla mainly occurs in the understory in natural forests. The regenerated seedlings grow poorly in a full light environment (Jin et al. 2008) and grow slowly in the environment with a canopy density greater than 0.8 (Yao et al. 2012). However, regenerated seedlings grow well in moderate light environment (e.g. canopy gap) (Liu 2012) mainly because $A$. holophylla seedlings can better absorb nutrients from soil when subjected to moderate light environment (Liu 2012), and their photosynthetic rates are relatively high (Jin et al. 2008). However, systematic 
studies on the differences in the photosynthetic characteristics of $A$. holophylla seedlings among different provenances under different light intensities have not been conducted. Therefore, the present work aimed to study systematically the changes in photosynthetic characteristics of $A$. holophylla seedlings from different provenances in weak light intensities, compare the differences in light adaptability of seedlings from different provenances, and explore the light acclimation mechanisms of seedlings by using setups with different light intensities in the greenhouse.

\section{Materials and methods}

\section{Acquisition, processing of seeds, and cultiva- tion of seedlings}

Seeds were collected from six provenances with a natural distribution area of $A$. holophyl- $l a$ and included the following areas: Xiuyan Manchu Autonomous County, Fengcheng City, Huanren Manchu Autonomous County, Xinbin Manchu Autonomous County, Qingyuan Manchu Autonomous County in Liaoning Province and Ningan City in Heilongjiang Province in Northeast China. The climatic conditions varied among different provenances (Table 1).

Seeds from each provenance were collected from late September to early October 2011. Seed trees were selected from individual $A$. holophylla plants that are superior in local coniferous and broad-leaved mixed forest. The heights of the seed trees were greater than 30 $\mathrm{m}$, and the tree ages exceeded $40 \mathrm{a}$. The cones were picked, desiccated, and threshed to obtain seeds. The wings of the seeds were removed in the modulation process in local forest farms and sent to the laboratory afterward. The seeds were cleared from debris and sealed in Ziploc plastic bags in the laboratory before being stored in the refrigerator at $4{ }^{\circ} \mathrm{C}$.

In the laboratory, seeds were soaked in warm

Table 1 Geographical location and climatic conditions of six Abies holophylla provenances in Northeast China

\begin{tabular}{llllllc}
\hline Factors & \multicolumn{2}{l}{ Provenances } & & & \\
\cline { 2 - 7 } & Xiuyan & Fengcheng & Huanren & Xinbin & Qingyuan & Ningan \\
\hline North latitude & $40^{\circ} 16^{\prime} 49^{\prime \prime}$ & $40^{\circ} 27^{\prime} 08^{\prime \prime}$ & $41^{\circ} 16^{\prime} 02^{\prime \prime}$ & $41^{\circ} 44^{\prime} 03^{\prime \prime}$ & $42^{\circ} 06^{\prime} 02^{\prime \prime}$ & $44^{\circ} 10^{\prime} 06^{\prime \prime}$ \\
East longitude & $123^{\circ} 17^{\prime} 14^{\prime \prime}$ & $124^{\circ} 04^{\prime} 01^{\prime \prime}$ & $125^{\circ} 21^{\prime} 40^{\prime \prime}$ & $125^{\circ} 02^{\prime} 34^{\prime \prime}$ & $124^{\circ} 55^{\prime} 27^{\prime \prime}$ & $129^{\circ} 24^{\prime} 46^{\prime \prime}$ \\
Mean annual temperature $\left({ }^{\circ} \mathrm{C}\right)$ & 7.20 & 6.90 & 6.30 & 5.80 & 5.90 & 3.50 \\
$\begin{array}{l}\text { Mean temperature in January } \\
\left({ }^{\circ} \mathrm{C}\right)\end{array}$ & -9.90 & -17.10 & -12.40 & -13.90 & -14.60 & -18.70 \\
Mean temperature in July $\left({ }^{\circ} \mathrm{C}\right)$ & 23.20 & 28.20 & 23.00 & 23.70 & 23.10 & 21.90 \\
$\begin{array}{l}\text { Annual temperature difference } \\
\left({ }^{\circ} \mathrm{C}\right)\end{array}$ & 33.10 & 45.30 & 35.40 & 37.60 & 37.70 & 40.60 \\
Accumulated temperature $\left({ }^{\circ} \mathrm{C}\right)$ & 3151 & 3300 & 3184 & 3000 & 2853 & 2575 \\
Mean annual precipitation $(\mathrm{mm})$ & 855 & 1040 & 815 & 780 & 770 & 500 \\
Mean annual evaporation $(\mathrm{mm})$ & 1214 & 1237 & 1213 & 1225 & 1275 & 1320 \\
Aridity index & 0.70 & 0.84 & 0.67 & 0.64 & 0.60 & 0.38 \\
Temperature-humidity index & 0.10 & 0.12 & 0.11 & 0.11 & 0.10 & 0.11 \\
Sunshine duration (h) & 2373 & 2390 & 2370 & 2386 & 2419 & 2650 \\
Frost-free period (d) & 151 & 156 & 140 & 130 & 130 & 130 \\
\hline
\end{tabular}


water at $45^{\circ} \mathrm{C}$ (initial temperature) in mid-August 2012. The soaked time continued for 48 $\mathrm{h}$, and the water was renewed every $12 \mathrm{~h}$. After that, seeds were soaked in $0.5 \% \mathrm{KMnO}_{4}$ solution to disinfect for $3 \mathrm{~h}$, and sterilized seeds were thoroughly rinsed with purified water. The pure seeds were then mixed with the appropriate amount of sand before the mixture was placed in the artificial climate chamber to accelerate germination at the variable temperatures (Pan 2011). Most seeds germinated about $15 \mathrm{~d}$ later. The gemmiparous seeds were sown into containers (cylinder-shaped container, 10 $\mathrm{cm}$ in height and $5 \mathrm{~cm}$ in diameter) when the length of the radicle was equal to the length of seed. The culture medium for seedlings is the mixture of peat and vermiculite (1:1 by volume). Entire container seedlings were planted during the end of August.

\section{Experimental design}

Four light gradients were set up with different layers of black shade nets within the glasshouse of Silviculture discipline in Experimental Forest Farm of Beijing Forestry University. The average light intensity was $650 \mu \mathrm{mol} \cdot \mathrm{m}^{-2} \cdot \mathrm{s}^{-1}$ within the glasshouse. The setup with $100 \%$ of full light (L0) served as a control. Three weak light intensity treatments were $75.08 \%$, $55.42 \%$, and $30.38 \%$ of full light, which were set up with one layer (L1), two layers (L1), and three layers (L3) of nets, respectively. A total of 300 robust seedlings selected from each provenance were moved into the shade nets in early September, including five repetitions from each plot. Each plot had 15 seedlings and 120 plots in total. The seedlings were fertilized weekly under exponential fertilization regimes (Duan et al. 2013) and were irrigated weekly. All seedlings were harvested $60 \mathrm{~d}$ later in early November.

\section{Measurement of light response curve and $\mathrm{CO}_{2}$ response curve}

Before the end of the experiment, five robust seedlings were selected from each plot. The light response curve and $\mathrm{CO}_{2}$ response curve of each seedling were measured using a portable photosynthetic measurement system (LI-6400, Li-Cor Inc., USA) according to the method of $\mathrm{Xu}$ et al. (2012). During measurement of light response curve, the $\mathrm{CO}_{2}$ concentration was maintained at $400 \mu \mathrm{mol} \mathrm{mol}{ }^{-1}$ by using a $\mathrm{CO}_{2}$ injection system in the leaf chamber. Air velocity, temperature, and air relative humidity were maintained at $500 \mathrm{~mL} \mathrm{~min}{ }^{-1},(25 \pm 0.5)$ ${ }^{\circ} \mathrm{C}$, and $(40 \pm 5) \%$, respectively. Photosynthetic photon flux density was changed through a red-blue light source, which is attached to the leaf chamber when the measurements were taken. During measurement of $\mathrm{CO}_{2}$ response curve, photosynthetic photon flux density was maintained at $450 \mu \mathrm{mol} \mathrm{m} \mathrm{m}^{-2} \mathrm{~s}^{-1}$ by using a red-blue light source in the leaf chamber. The maintained air velocity, temperature, and air relative humidity parameters were the same as in the measurements of the light response curve. $\mathrm{CO}_{2}$ concentration was changed using a $\mathrm{CO}_{2}$ injection system when measurements were taken.

\section{Statistical analysis}

All experimental data were collated and mapped by Microsoft Office Excel 2007. Multiple comparisons and analysis of variance were conducted by SPSS 16.0. The calculation of aridity index of each provenance was equal to the local mean annual precipitation divided by the local mean annual evaporation, and the temperature-humidity index was equal to the local aridity index divided by the mean annual temperature.

The non-rectangular hyperbolic photosynthetic model (Farquhar et al. 1980) was adopted in the fitting analysis of nonlinear regression of the light response curve and $\mathrm{CO}_{2}$ response 
curve. Photosynthetic parameters, such as max net photosynthetic rate $\left(\mathrm{P}_{\max }\right)$, photosynthetic capacity $\left(\mathrm{P}_{\text {cap }}\right)$, carboxylation efficiency $(\mathrm{CE})$, $\mathrm{CO}_{2}$ compensation point (CCP), $\mathrm{CO}_{2}$ saturation point (CSP), apparent quantum yield (AQY), light compensation point (LCP), light saturation point (LSP), dark respiration rate $\left(\mathrm{R}_{\mathrm{d}}\right)$, and photo respiration rate $\left(\mathrm{R}_{\mathrm{p}}\right)$, were calculated using the method of Xu et al. (2012). Percentage of respiration (PR) was the ratio of $\mathrm{R}_{\mathrm{d}}$-plus- $\mathrm{R}_{\mathrm{p}}$ to $\mathrm{P}_{\max }$. Genetic parameters, such as phenotypic coefficient of variation (PCV), genetic coefficient of variation (GCV), repeatability (R), and broad-sense heritability $\left(\mathrm{H}^{2}\right)$, were calculated according to the method of Zhao et al. (2011).

The sensitivity of each provenance to different light intensities was analyzed using grade scoring method of fuzzy mathematics (Jiang et al. 2008). The rate of change of each parameter of six provenances under the strongest (L0) and the weakest light intensity was scored. The rate of change was represented by the percentage of difference value between the values of L0 and L3, and the absolute values of the rate of change were graded as the score of sensitivity. The score of sensitivity of each parameter of each provenance was added to obtain the total score of sensitivity of each provenance. The larger the total score, the higher the sensitivity.

\section{Results}

Effect of light intensities on the foliar $\mathrm{CO}_{2}$ assimilation capacity of $A$. holophylla seedlings from different provenances

The changed light intensity and provenance had a highly significant effect $(P<0.01)$ on the parameters of foliar $\mathrm{CO}_{2}$ assimilation capacity of $A$. holophylla seedlings. The interactions between light intensity and provenance also had a highly significant effect $(P<0.01)$ on the parameters of foliar $\mathrm{CO}_{2}$ assimilation capacity, except for CE (Table 2). The differences that caused by provenances of $\mathrm{P}_{\max }$, $\mathrm{P}_{\text {cap }}, \mathrm{CE}, \mathrm{CCP}$ and CSP accounted for $19.73 \%$, $9.16 \%, 29.90 \%, 35.92 \%$, and $25.76 \%$ of total differences, respectively.

$\mathrm{P}_{\text {max }}$ and $\mathrm{P}_{\text {cap }}$ of $A$. holophylla seedlings from all six provenances decreased by $50.33 \%$ to $16.96 \%$ and $63.84 \%$ to $48.15 \%$, respectively, accompanied by a drop in light intensity (Figure $1 \mathrm{a}, \mathrm{b})$ and showed a highly significant

Table 2 Results of analysis of variance (ANOVA) on the foliar photosynthetic parameters of Abies holophylla seedlings from different provenances under different light intensities

\begin{tabular}{|c|c|c|c|c|c|c|}
\hline \multirow{2}{*}{ Variant Sources } & \multicolumn{2}{|l|}{$\underline{\mathrm{LC}}$} & \multicolumn{2}{|l|}{$\underline{P}$} & \multicolumn{2}{|l|}{$\underline{\mathrm{LC}} \times \mathrm{P}$} \\
\hline & $F$ & Sig. & $F$ & Sig. & $F$ & Sig. \\
\hline $\mathrm{P}_{m}$ & 231.636 & 0.000 & 59.605 & 0.000 & 10.786 & 0.000 \\
\hline $\mathrm{P}^{\max }$ & 224.051 & 0.000 & 22.979 & 0.000 & 3.958 & 0.000 \\
\hline $\mathrm{CE}$ & 9.089 & 0.000 & 4.203 & 0.003 & 0.763 & 0.709 \\
\hline CCP & 170.772 & 0.000 & 100.050 & 0.000 & 7.685 & 0.000 \\
\hline CSP & 3868.000 & 0.000 & 1422.000 & 0.000 & 229.892 & 0.000 \\
\hline AQY & 9.397 & 0.000 & 4.945 & 0.001 & 0.345 & 0.986 \\
\hline LCP & 413.853 & 0.000 & 269.537 & 0.000 & 20.540 & 0.000 \\
\hline LSP & 145.774 & 0.000 & 47.130 & 0.000 & 8.534 & 0.000 \\
\hline $\mathrm{R}_{\mathrm{d}}$ & 119.064 & 0.000 & 26.435 & 0.000 & 5.219 & 0.000 \\
\hline$R^{d}$ & 202.275 & 0.000 & 43.580 & 0.000 & 10.128 & 0.000 \\
\hline$P R$ & 117.174 & 0.000 & 58.475 & 0.000 & 12.356 & 0.000 \\
\hline
\end{tabular}

Note. Abbreviations: LC - light intensity, P - provenance, Pmax - net photosynthetic rate, Pcap - photosynthetic capacity, $\mathrm{CE}$ - carboxylation efficiency, CCP - CO2 compensation point, CSP - CO2 saturation point, AQY - apparent quantum yield, LCP - light compensation point, LSP - light saturation point, Rd - dark respiration rate, Rp - photo respiration rate, PR - percentage of respiration, $F$ - F value, Sig. - significance level. 


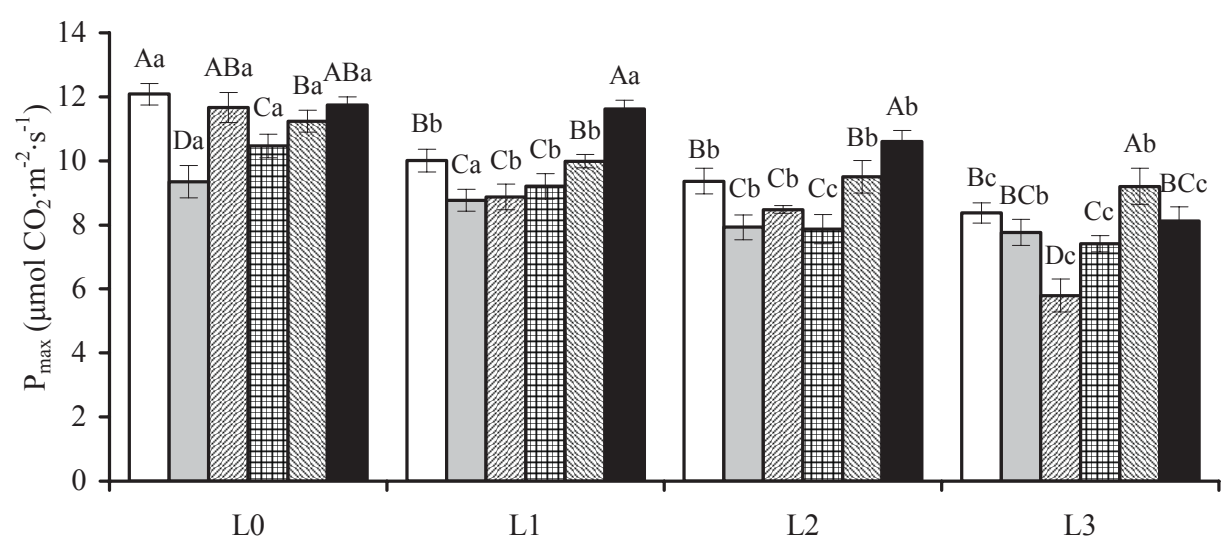

(a)
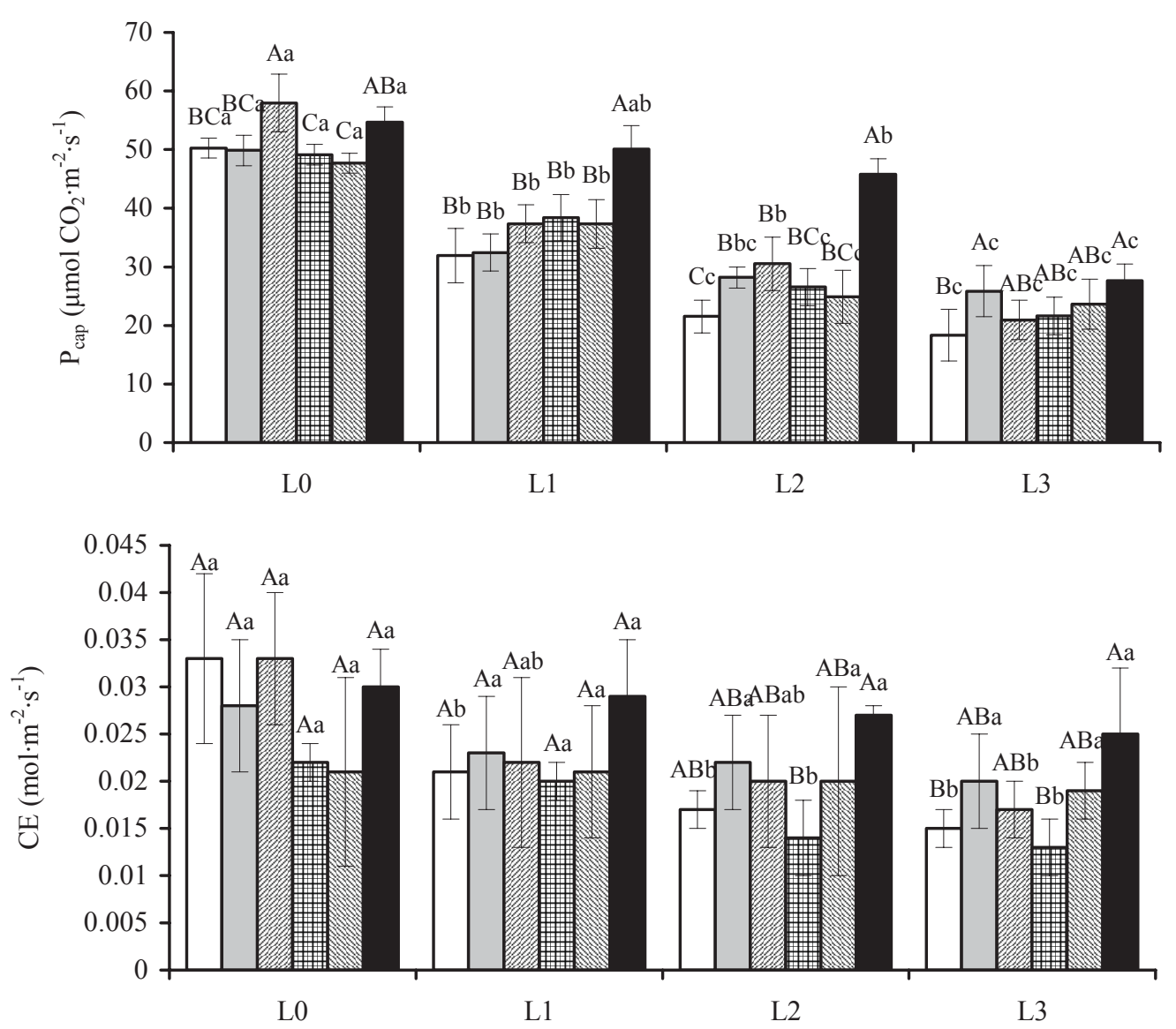

(c)

Figure 1 Effect of light intensities on the foliar $\mathrm{CO}_{2}$ assimilation capacity of Abies holophylla seedlings from different provenances. (a) $\mathrm{P}_{\max }$, (b) $\mathrm{P}_{\text {cap }}$, (c) CE, (d) CCP, and (e) CSP. Error bars are SDs. Different capital letters above the error bars represent significant differences among different provenances under the same light intensity at the 0.05 level, and different small letters above the error bars represent significant differences among different light intensities of the same provenance at the 0.05 level

difference $(P<0.01)$ among different light intensities. CE decreased with decreased light intensity (Figure 1c). Xinbin and Xiuyan provenances showed highly significant differences 186
$(P<0.01)$ and significant differences $(P<$ $0.05)$ among different light intensities. CCP and CSP decreased by $33.03 \%$ to $10.85 \%$ and $43.44 \%$ to $19.67 \%$, respectively, with decreased 

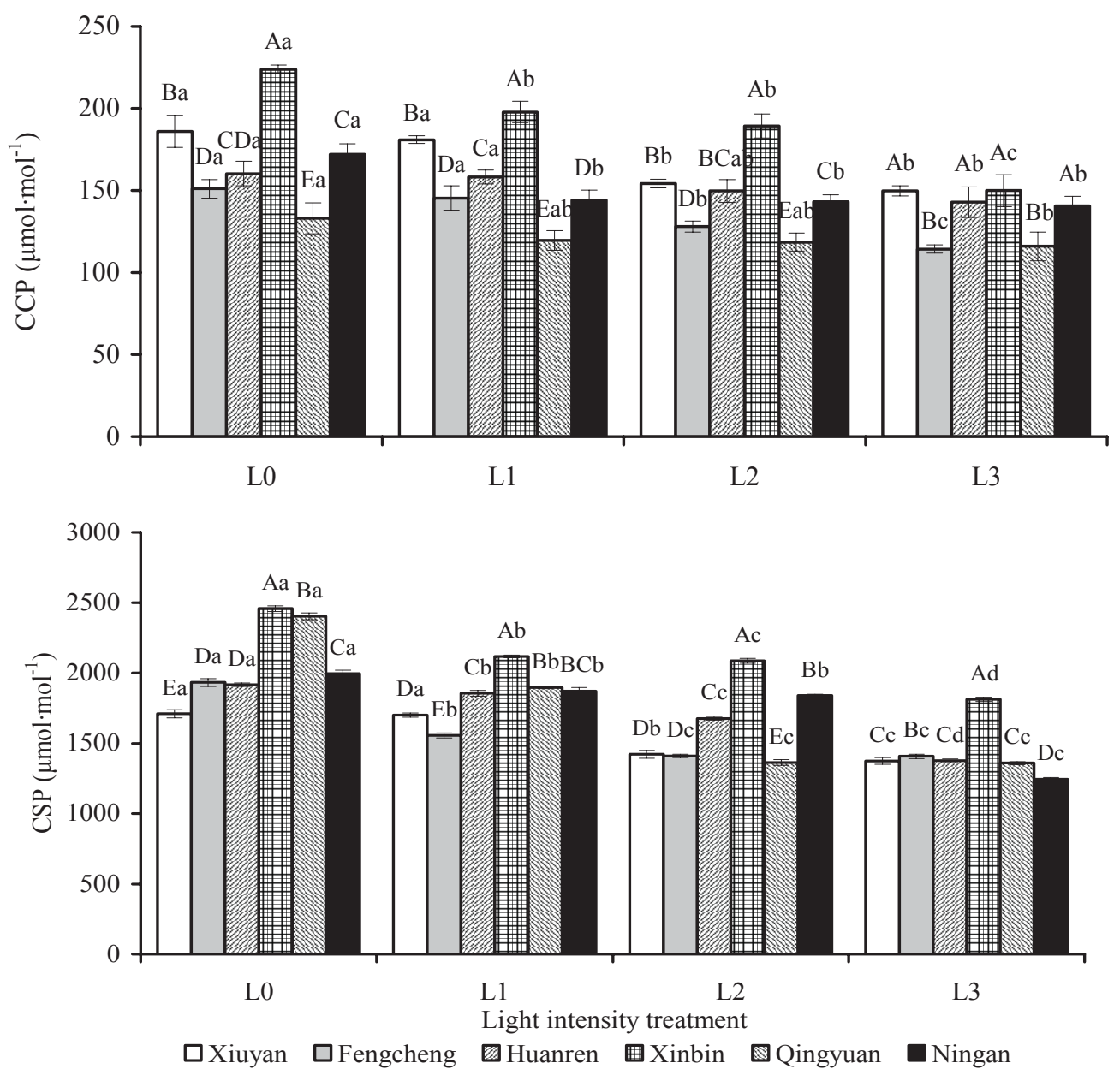

(e)

Figure 1 (continuation)

light intensity (Figure 1d, e), except for Huanren and Qingyuan provenances, which had the smallest decrease in CCP with no significant difference between different light intensities. $\mathrm{CCP}$ and CSP of all other provenances showed highly significant differences $(P<0.01)$ among different light intensities.

\section{Effect of light intensities on the foliar light utilization capacity of $A$. holophylla seedlings from different provenances}

The changed light intensity and provenance had a highly significant effect $(P<0.01)$ on the foliar light utilization capacity of $A$. holophylla seedlings. Interaction between light intensity and provenance also showed a highly significant effect $(P<0.01)$ on foliar light uti- (d) 
Effect of light intensities on the foliar respiration depletion of $A$. holophylla seedlings from different provenances

The changed light intensity and provenance had a highly significant effect $(P<0.01)$ on the parameters of foliar respiration depletion of A. holophylla seedlings. Interactions between light intensity and provenance also had a highly significant effect $(P<0.01)$ on the parameters of foliar respiration depletion (Table 2). The differences in $\mathrm{R}_{\mathrm{d}}, \mathrm{R}_{\mathrm{p}}$ and $\mathrm{PR}$ due to provenance accounted for $17.54 \%, 17.02 \%$, and $31.10 \%$ of the total differences, respectively.

As the light intensity dropped, the $\mathrm{R}_{\mathrm{d}}, \mathrm{R}_{\mathrm{p}}$, and $\mathrm{PR}$ of $A$. holophylla seedlings from six provenances decreased by $68.52 \%$ to $45.35 \%$, $63.41 \%$ to $21.22 \%$, and $46.88 \%$ to $11.96 \%$, respectively (Figure 3a-c). Except for the $\mathrm{R}_{\mathrm{p}}$ and PR of Qingyuan provenance, which showed no significant difference between different light intensities, the $R_{d}, R_{p}$, and PR of all other provenances showed highly significant differences $(P<0.01)$ at different light intensities.

\section{Genetic variation analysis of foliar photosyn- thetic parameters of $A$. holophylla seedlings from different provenances under different light intensities}

Except for CE, the differences in terms of $\mathrm{P}_{\text {max }}$, $\mathrm{P}_{\text {cap }}$, CCP and CSP of $A$. holophylla seedlings from six provenances were highly significant $(P<0.01)$ under each light intensity treatment (Table 3). Under different light intensities, the PCV and GCV of the parameters of foliar $\mathrm{CO}_{2}$ assimilation capacity ranged from $8.43 \%$ to $32.23 \%$ and $4.87 \%$ to $19.76 \%$, respectively. Except for the R of CE, which was about 0.5, the $\mathrm{R}$ of the parameters of foliar $\mathrm{CO}_{2}$ assimilation capacity was above 0.8 , which indicates a higher genetic stability of foliar $\mathrm{CO}_{2}$ assimilation capacity in the A. holophylla population. The $\mathrm{H}^{2}$ of $\mathrm{P}_{\text {max }}, \mathrm{CCP}$, and CSP was higher than 0.7 , which suggests that the foliar $\mathrm{CO}_{2}$ assimilation capacity of $A$. holophylla seedlings from six provenances was strongly controlled by genetic factors.

The differences in AQY of A. holophylla seedlings from six provenances were not significant difference $(P<0.05)$ under each light intensity treatment, but the differences in LCP and LSP showed a highly significant difference $(P<0.01)$ under each light intensity treatment (Table 3). Under different light intensities, the values of PCV of LCP reached the maximum, and the value range was the broadest among the parameters of foliar light utilization capacity. However, the value and the value range of PCV of LSP showed opposing trends; the GCV showed a similar trend. The R of LCP and LSP was above 0.8 , which indicates a high genetic stability of foliar light utilization capacity in the A. holophylla population. The $\mathrm{H}^{2}$ values of LCP and LSP were above 0.4 , implying moderate and over heritability, respectively. This finding shows that the foliar light utilization capacity of $A$. holophylla seedlings from six provenances is also strongly controlled by genetic factors.

All of the differences in $\mathrm{R}_{\mathrm{d}}, \mathrm{R}_{\mathrm{p}}$, and PR of $A$. holophylla seedlings from six provenances were all highly significant $(P<0.01)$ under each light intensity treatment (Table 3 ). Under different light intensities, the PCV of $R_{d}, R_{p}$, and $\mathrm{PR}$ ranged from $12.18 \%$ to $39.11 \%$ and were slightly higher than $8.14 \%$ to $23.48 \%$ of GCV. The $R$ of $R_{d}, R_{p}$, and PR ranged from 0.84 to 0.98 . The $\mathrm{H}^{2}$ values ranged from 0.46 to 0.90 , which indicates that the foliar respiration depletion of $A$. holophylla seedlings from six provenances had high genetic stability and was also strongly controlled by genetic factors.

On the basis of the above genetic variation analysis, the change in trend of PCV of foliar photosynthetic parameters of A. holophylla seedlings from different provenances was found to be similar to the change in the trend of GCV in response to changed light intensity. The change in the $\mathrm{R}$ was also similar to the change in the trend of $\mathrm{H}^{2}$. 
Table 3 Genetic parameters of foliar photosynthetic parameters of Abies holophylla seedlings from different provenances under different light intensities

\begin{tabular}{|c|c|c|c|c|c|c|c|c|c|}
\hline Parameters & Treatments & $F$ & Sig. & Mean & SD & $\begin{array}{l}\mathrm{PCV} \\
(\%)\end{array}$ & $\begin{array}{l}\text { GCV } \\
(\%)\end{array}$ & $\mathrm{R}$ & $\mathrm{H}^{2}$ \\
\hline \multirow{4}{*}{$\mathrm{P}_{\max }$} & L0 & 20.680 & 0.000 & 11.09 & 1.01 & 9.12 & 6.34 & 0.95 & 0.77 \\
\hline & L1 & 30.009 & 0.000 & 9.74 & 1.04 & 10.65 & 7.59 & 0.97 & 0.83 \\
\hline & L2 & 22.028 & 0.000 & 8.96 & 1.05 & 11.71 & 8.18 & 0.95 & 0.78 \\
\hline & L3 & 21.381 & 0.000 & 7.78 & 1.14 & 14.60 & 10.17 & 0.95 & 0.77 \\
\hline \multirow{4}{*}{$\mathrm{P}_{\text {cap }}$} & L0 & 5.880 & 0.006 & 51.60 & 4.35 & 8.43 & 4.87 & 0.83 & 0.45 \\
\hline & $\mathrm{L} 1$ & 8.484 & 0.001 & 37.92 & 6.98 & 18.40 & 11.49 & 0.88 & 0.56 \\
\hline & $\mathrm{L} 2$ & 18.748 & 0.000 & 29.58 & 8.48 & 28.66 & 19.76 & 0.95 & 0.75 \\
\hline & L3 & 7.954 & 0.008 & 23.00 & 4.51 & 19.59 & 9.76 & 0.87 & 0.54 \\
\hline \multirow{4}{*}{$\mathrm{CE}$} & L0 & 1.679 & 0.214 & 0.03 & 0.01 & 27.72 & - & 0.40 & - \\
\hline & L1 & 1.849 & 0.541 & 0.02 & 0.01 & 26.48 & - & 0.46 & - \\
\hline & $\mathrm{L} 2$ & 1.711 & 0.206 & 0.02 & 0.01 & 32.23 & - & 0.42 & - \\
\hline & L3 & 2.895 & 0.061 & 0.02 & 0.01 & 29.48 & - & 0.65 & - \\
\hline \multirow{4}{*}{$\mathrm{CCP}$} & L0 & 55.696 & 0.000 & 171.03 & 30.25 & 17.69 & 12.92 & 0.98 & 0.90 \\
\hline & L1 & 73.508 & 0.000 & 157.71 & 26.79 & 16.99 & 12.50 & 0.99 & 0.92 \\
\hline & $\mathrm{L} 2$ & 66.122 & 0.000 & 147.16 & 23.59 & 16.03 & 11.76 & 0.98 & 0.92 \\
\hline & L3 & 15.568 & 0.000 & 135.57 & 16.43 & 12.12 & 8.22 & 0.94 & 0.71 \\
\hline \multirow{4}{*}{ CSP } & L0 & 481.245 & 0.000 & 2068.88 & 279.08 & 13.49 & 10.12 & 0.99 & 0.99 \\
\hline & L1 & 361.590 & 0.000 & 1833.14 & 179.55 & 9.79 & 7.34 & 0.99 & 0.98 \\
\hline & L2 & 818.059 & 0.000 & 1632.27 & 271.73 & 16.65 & 12.51 & 0.99 & 0.99 \\
\hline & L3 & 474.548 & 0.000 & 1428.89 & 184.57 & 12.92 & 9.69 & 0.99 & 0.99 \\
\hline \multirow{4}{*}{ AQY } & L0 & 2.239 & 0.117 & 0.02 & 0.01 & 34.74 & - & 0.55 & - \\
\hline & L1 & 1.703 & 0.632 & 0.02 & 0.01 & 32.95 & - & 0.41 & - \\
\hline & L2 & 1.351 & 0.309 & 0.03 & 0.01 & 23.19 & - & 0.26 & - \\
\hline & L3 & 2.638 & 0.078 & 0.03 & 0.01 & 21.02 & - & 0.62 & - \\
\hline \multirow{4}{*}{ LCP } & L0 & 129.141 & 0.000 & 21.59 & 9.86 & 45.66 & 33.93 & 0.99 & 0.96 \\
\hline & L1 & 86.463 & 0.000 & 15.81 & 9.23 & 58.39 & 43.11 & 0.99 & 0.93 \\
\hline & $\mathrm{L} 2$ & 66.675 & 0.000 & 7.70 & 6.56 & 85.17 & 62.52 & 0.99 & 0.92 \\
\hline & L3 & 35.385 & 0.000 & 5.17 & 4.70 & 90.99 & 65.34 & 0.97 & 0.85 \\
\hline \multirow{4}{*}{ LSP } & L0 & 41.641 & 0.000 & 468.02 & 83.66 & 17.88 & 12.93 & 0.98 & 0.87 \\
\hline & L1 & 6.127 & 0.005 & 387.07 & 35.67 & 9.22 & 5.38 & 0.84 & 0.46 \\
\hline & $\mathrm{L} 2$ & 5.286 & 0.009 & 354.96 & 35.70 & 10.06 & 5.65 & 0.81 & 0.42 \\
\hline & $\mathrm{L} 3$ & 21.472 & 0.000 & 327.52 & 38.97 & 11.90 & 8.29 & 0.95 & 0.77 \\
\hline \multirow{4}{*}{$\mathrm{R}_{\mathrm{d}}$} & L0 & 14.838 & 0.000 & 0.84 & 0.17 & 20.69 & 13.92 & 0.93 & 0.69 \\
\hline & L1 & 16.282 & 0.000 & 0.57 & 0.17 & 30.46 & 20.83 & 0.94 & 0.74 \\
\hline & $\mathrm{L} 2$ & 6.247 & 0.004 & 0.49 & 0.14 & 28.73 & 16.87 & 0.84 & 0.46 \\
\hline & L3 & 6.945 & 0.003 & 0.34 & 0.13 & 39.11 & 23.48 & 0.86 & 0.48 \\
\hline \multirow{2}{*}{$\mathrm{R}_{\mathrm{p}}$} & L0 & 36.439 & 0.000 & 4.76 & 1.11 & 23.26 & 16.73 & 0.97 & 0.86 \\
\hline & L1 & 12.922 & 0.000 & 3.55 & 0.61 & 17.08 & 11.34 & 0.92 & 0.67 \\
\hline
\end{tabular}


Table 3 (continuation)

\begin{tabular}{|c|c|c|c|c|c|c|c|c|c|}
\hline Parameters & Treatments & $F$ & Sig. & Mean & SD & $\begin{array}{l}\text { PCV } \\
(\%)\end{array}$ & $\begin{array}{l}\text { GCV } \\
(\%)\end{array}$ & $\mathrm{R}$ & $\mathrm{H}^{2}$ \\
\hline & L2 & 9.591 & 0.000 & 2.89 & 0.55 & 19.02 & 12.13 & 0.90 & 0.59 \\
\hline & L3 & 10.399 & 0.000 & 2.44 & 0.57 & 23.56 & 15.19 & 0.90 & 0.61 \\
\hline \multirow{4}{*}{ PR } & L0 & 54.877 & 0.000 & 50.51 & 8.48 & 16.78 & 12.25 & 0.98 & 0.90 \\
\hline & L1 & 13.710 & 0.000 & 42.42 & 5.17 & 12.18 & 8.14 & 0.93 & 0.68 \\
\hline & $\mathrm{L} 2$ & 10.316 & 0.000 & 37.75 & 5.18 & 13.71 & 8.83 & 0.90 & 0.61 \\
\hline & L3 & 26.651 & 0.000 & 36.32 & 8.31 & 22.89 & 16.19 & 0.96 & 0.81 \\
\hline
\end{tabular}

Note. Abbreviations: F - F value, Sig. - significance level, Mean - mean value, SD - standard deviation, PCV - phenotypic coefficient of variation, GCV - genetic coefficient of variation, R - repeatability, and H2 - broad-sense heritability.

Comprehensive assessment of the sensitivities of $A$. holophylla seedlings from different provenances to changed light intensities

The sequence of the reaction sensitivities of $A$. holophylla seedlings from six provenances to changed light intensities was Xinbin> Xiuyan $>$ Huanren $>$ Ningan $>$ Fengcheng $>$ Qingyuan (Table 4). The above results indicate that the adaptability of the seedlings from Xinbin provenance was the strongest when subjected to weak light intensity, and the rangeability of foliar photosynthetic parameters was the wid- est; thus, its sensitivity was the highest. The adaptability of the seedlings from Qingyuan provenance was the weakest, and the effect of changed light intensities on foliar photosynthetic parameters was the smallest; thus, its sensitivity was the lowest.

Correlation was found between the sensitivities of $A$. holophylla seedlings to changed light intensities and the geological and climatic conditions of $A$. holophylla provenances (Table 5). The correlation between sensitivity scores and annual temperature difference was the strongest $(r=-0.717)$, followed by mean tempera-

Table 4 Sensitivity analysis of Abies holophylla seedlings from different provenances to changed light intensities

\begin{tabular}{|c|c|c|c|c|c|c|}
\hline \multirow{2}{*}{ Parameters } & \multicolumn{6}{|c|}{ Provenances } \\
\hline & Xiuyan & Fengcheng & Huanren & Xinbin & Qingyuan & Ningan \\
\hline $\mathrm{P}_{\max }$ & 2 & 1 & 3 & 2 & 1 & 2 \\
\hline $\mathrm{P}_{\text {cap }}$ & 4 & 3 & 4 & 3 & 3 & 3 \\
\hline $\mathrm{CE}$ & 3 & 2 & 3 & 3 & 1 & 1 \\
\hline CCP & 1 & 2 & 1 & 3 & 1 & 1 \\
\hline CSP & 1 & 2 & 2 & 2 & 3 & 2 \\
\hline AQY & 4 & 2 & 4 & 3 & 2 & 3 \\
\hline LCP & 4 & 3 & 4 & 4 & 4 & 4 \\
\hline LSP & 2 & 2 & 1 & 2 & 2 & 2 \\
\hline $\mathrm{R}_{\mathrm{d}}$ & 3 & 3 & 4 & 4 & 3 & 4 \\
\hline $\mathrm{R}_{\mathrm{p}}$ & 4 & 3 & 3 & 4 & 2 & 2 \\
\hline $\mathrm{PR}$ & 3 & 1 & 1 & 3 & 1 & 1 \\
\hline Total score & 31 & 24 & 30 & 33 & 23 & 25 \\
\hline Sensitivity order & 2 & 5 & 3 & 1 & 6 & 4 \\
\hline
\end{tabular}


ture in January $(r=0.654)$ and mean annual evaporation $(r=-0.584)$. However, all the correlations were not statistically significant $(P<$ $0.05)$. The correlation coefficients between sensitivity scores and other geological and climatic factors of $A$. holophylla provenances were smaller than the three above mentioned values.

The results showed that temperature range and effective precipitation of provenance probably were the main factors that affected the sensitivities of $A$. holophylla seedlings to changed light intensities on some level. The A. holophylla seedlings from the large annual temperature difference and high effective precipitation area were less sensitive to changed light intensities compared with the seedlings from the small annual temperature difference and low effective precipitation area, which had lower photosynthetic plasticity in changed light environments. Therefore, the adaptability to light intensities of the latter was worse than that of the former.

\section{Discussion}

The light response curve and the $\mathrm{CO}_{2}$ response curve of plant photosynthesis are significant in understanding the photochemical efficiency in photochemical processes of plants (Wientjes et al. 2013). $\mathrm{P}_{\max }$ is an important indicator that directly reflects the photosynthetic capacity of plants. All $\mathrm{P}_{\max }$ of A. holophylla seedlings from six provenances were significantly lower than the control (L0) under weak light intensity treatments in varying degrees (Figure 1a). However, the range of declines was broad, which indicates that variations existed among A. holophylla seedlings from different provenances to adapt with changed light intensities. The increase in atmospheric $\mathrm{CO}_{2}$ concentration can promote plant photosynthesis at a certain range. The $\mathrm{P}_{\text {cap }}$ that could be achieved by $A$. holophylla seedlings from different provenances varied under different light environments (Figure 1b), which suggests that differences in the foliar $\mathrm{CO}_{2}$ assimilation capacity exist among different provenances under changed light intensities. CE of A. holophylla seedlings from different provenances decreased with decreased light intensity (Figure 1c). The results suggest that the activity and content of ribulose bisphosphate carboxylase/ oxygenase (Rubisco) were restrained under weak light environments, and different levels of restrictions led to differences among different provenances under same light intensities. The general characteristics of low CCP crops were high $\mathrm{P}_{\mathrm{n}}$ and yield. The $\mathrm{CCP}$ of $\mathrm{C}_{3}$ plants was about $30 \mu \mathrm{mol} \cdot \mathrm{mol}^{-1}$ to $70 \mu \mathrm{mol} \cdot \mathrm{mol}^{-1}$ (Mao et al. 2012), but the CCP of A. holophylla seedlings remained above $110 \mu \mathrm{mol} \cdot \mathrm{mol}^{-1}$ under the weakest light intensity (Figure 1d), implying a higher demand for $\mathrm{CO}_{2}$ by A. holophylla seedlings. High CSP reflects strong adaptability of plants to the environment (Shi et al. 2010). Obvious $\mathrm{CO}_{2}$ saturation was not

Table 5 Correlation coefficients of sensitivity scores and geological and climatic factors of Abies holophylla provenances

\begin{tabular}{llll}
\hline Factors & $\begin{array}{l}\text { Sensitivity } \\
\text { Scores }\end{array}$ & Factors & $\begin{array}{l}\text { Sensitivity } \\
\text { scores }\end{array}$ \\
\hline North latitude & -0.168 & Mean annual precipitation $(\mathrm{mm})$ & -0.106 \\
East longitude & -0.153 & Mean annual evaporation $(\mathrm{mm})$ & -0.584 \\
Mean annual temperature $\left({ }^{\circ} \mathrm{C}\right)$ & 0.143 & Aridity index & -0.026 \\
Mean temperature in January $\left({ }^{\circ} \mathrm{C}\right)$ & 0.654 & Temperature-humidity index & -0.401 \\
Mean temperature in July $\left({ }^{\circ} \mathrm{C}\right)$ & -0.441 & Sunshine duration $(\mathrm{h})$ & -0.353 \\
Annual temperature difference $\left({ }^{\circ} \mathrm{C}\right)$ & -0.717 & Frost-free period $(\mathrm{d})$ & -0.206 \\
Accumulated temperature $\left({ }^{\circ} \mathrm{C}\right)$ & 0.169 & & \\
\hline
\end{tabular}


observed in A. holophylla seedlings from all six provenances under different light intensities, consistent with the theory that the CSP of $\mathrm{C}_{3}$ plants was not obvious, and the $\mathrm{P}_{n}$ of $\mathrm{C}_{3}$ plants will rise with the increase with an increase in atmospheric $\mathrm{CO}_{2}$ concentration even if the $\mathrm{CO}_{2}$ concentration was relatively high (Larcher 2003).

The AQY of plants ranged from 0.03 to 0.05 in general (Galmés et al. 2013), but AQY of $A$. holophylla seedlings from different provenances ranged only from 0.01 to 0.04 (Figure 2a), which is slightly lower than the normal range. This result suggests that the foliar weak light utilization capacity of $A$. holophylla seedlings is not very strong under normal circumstances. The range of values in terms of LCP and LSP reflects the utilization range of light energy of plants. Lower LCP and LSP values were conducive to sufficient utilization of low photon density for plant photosynthesis under weak light environments, thereby increasing the accumulation of organic matter to maintain the carbon balance (Sun et al. 2007).

The decrease in $R_{d}$ resulted in dry matter accumulation, which allowed the plants to maintain a relatively stable state even though $\mathrm{P}_{\mathrm{n}}$ decreased under weak light intensities. The relative stability is of great significance to the plants that survive in a frequently changing environment (Song et al. 2009). The process of $\mathrm{R}_{\mathrm{p}}$ leads to the loss of carbon, which has been assimilated with $\mathrm{CO}_{2}$ ( $\mathrm{Zhu}$ et al. 2010). Therefore, the reduction in $\mathrm{R}_{\mathrm{p}}$ has a similar function with the reduction in $\mathrm{R}_{\mathrm{d}}$ under weak light environments, and also decreased the respiration depletion of photosynthetic products. In this study, the reduction in $R_{d}$ and $R_{p}$ under weak light environments (Figure $3 \mathrm{a}, \mathrm{b}$ ) could serve as a strategy of $A$. holophylla seedlings to maintain the accumulation of assimilation products. Notably, the PR decreased as the light intensity dropped (Figure 3c) but was still maintained at a high level. This finding demonstrates that photosynthetic products of $A$. holophylla seedlings were largely consumed by respiration and the amount of net accumulations of assimilation products was less, which is likely the main reason for the slow growth of $A$. holophylla seedlings during the seedling stage.

Generally, plants need a protection mechanism, a damage repair mechanism, or a combination of both to survive in stressful environments (Dinakar et al. 2012). Being a species which situating later succession stage in communities, the regenerated seedlings of A. holophylla were shaded for a long time in natural stand. The foliar weak light utilization capacity is critical to the survival and development of the species. In this study, the foliar photosynthesis of A. holophylla seedlings enhanced $\mathrm{CO}_{2}$ assimilation capacity through the reduction of CCP and CSP, improved weak light utilization capacity, and reduced light energy demand, thereby resulting in enhanced light utilization capacity through the increase in AQY and the reduction in LCP and LSP. Those changes also reduced respiration depletion though the decrease in $R_{d}$ and $R_{p}$. The above mentioned series of photosynthetic physiological changes in A. holophylla seedlings effectively improved the utilization efficiency of weak light, and made the plant fully adapted to the understory shaded environment to secure the energy required for survival and growth so that regeneration can be carried out.

Phenotypic variation is the result of genetic factors and environmental factors working together. The differences in terms of $\mathrm{CO}_{2}$ assimilation capacity, light utilization capacity, and respiration depletion of $A$. holophylla seedlings from six provenances were all highly significant $(P<0.01)$. PCV and GCV were highly varied, which indicates the large differences in photosynthetic parameters of A. holophylla seedlings among different provenances, implying abundant genetic variation basis and the enormous selection potentials. $R$ and $\mathrm{H}^{2}$ were proven to be reasons for the existence of differences in photosynthetic parameters among different provenances. The $R$ and $\mathrm{H}^{2}$ of each 


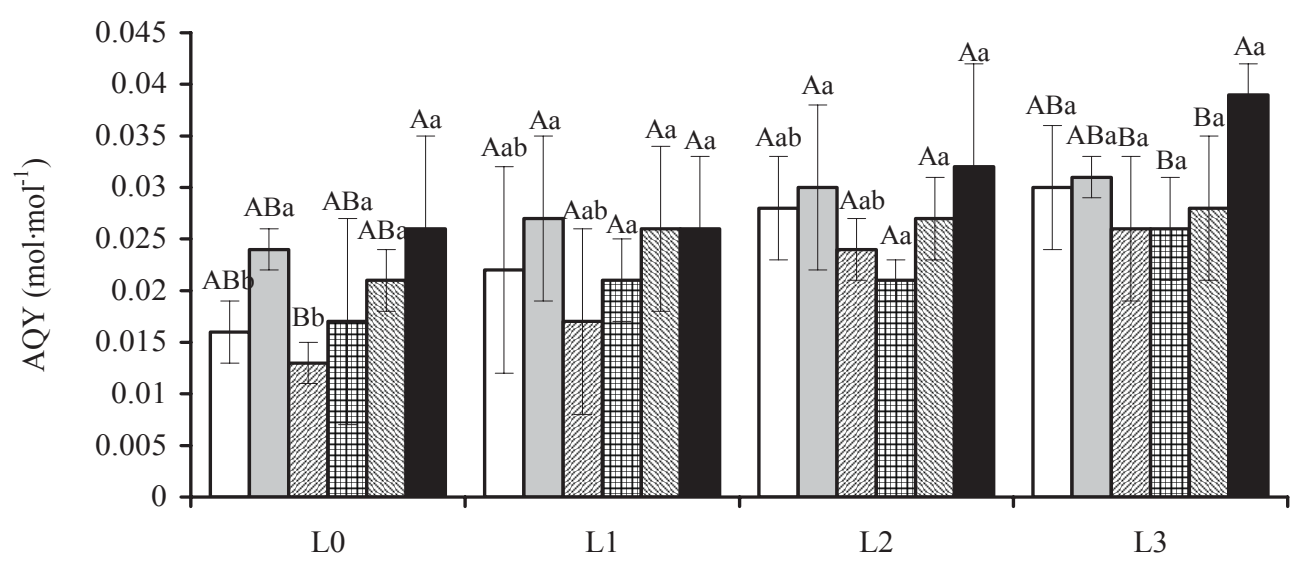

(a)

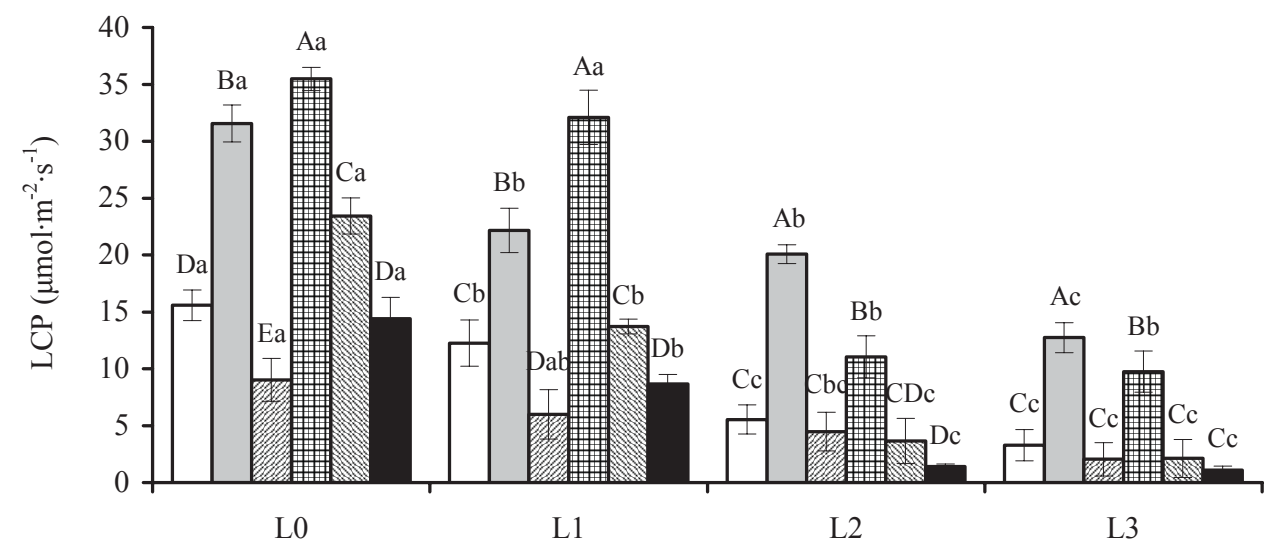

(b)

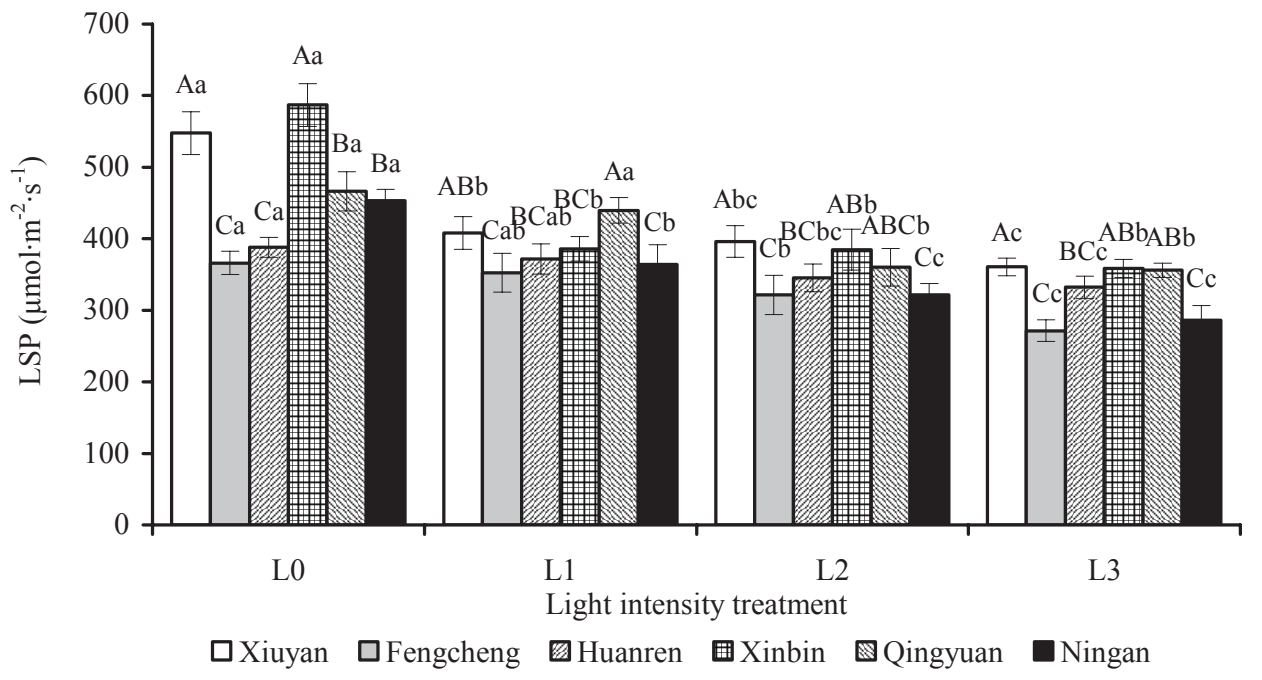

(c)

Figure 2 Effect of light intensities on the foliar light utilization capacity of Abies holophylla seedlings from different provenances. (a) AQY, (b) LCP, and (c) LSP. Same notes as Figure 1

photosynthetic parameter were higher than other factors, thus indicating that the variations in the parameters were strongly controlled by genetic factors instead of environmental factors. The genetic stability of populations was also relatively high.
The foliar photosynthetic characteristics of A. holophylla seedlings were mainly controlled by genetic factors, which led to different sensitivities and different adaptabilities of seedlings from different provenances to changed light intensities (Table 4), which resulted in signifi- 


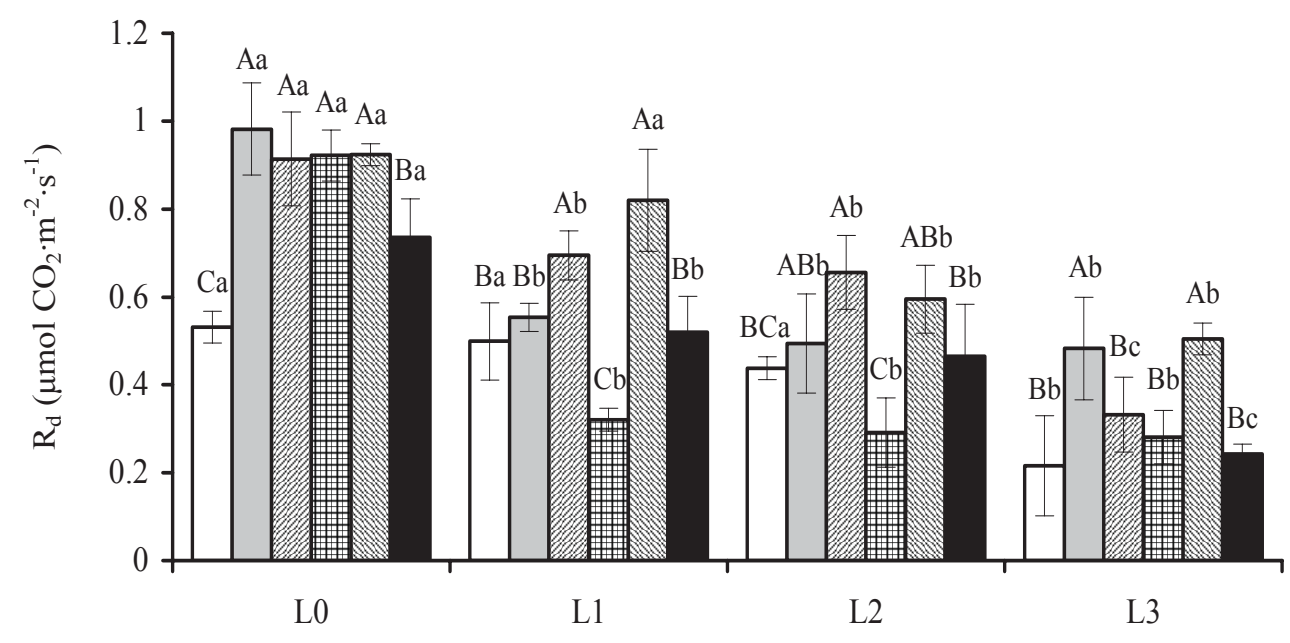

(a)

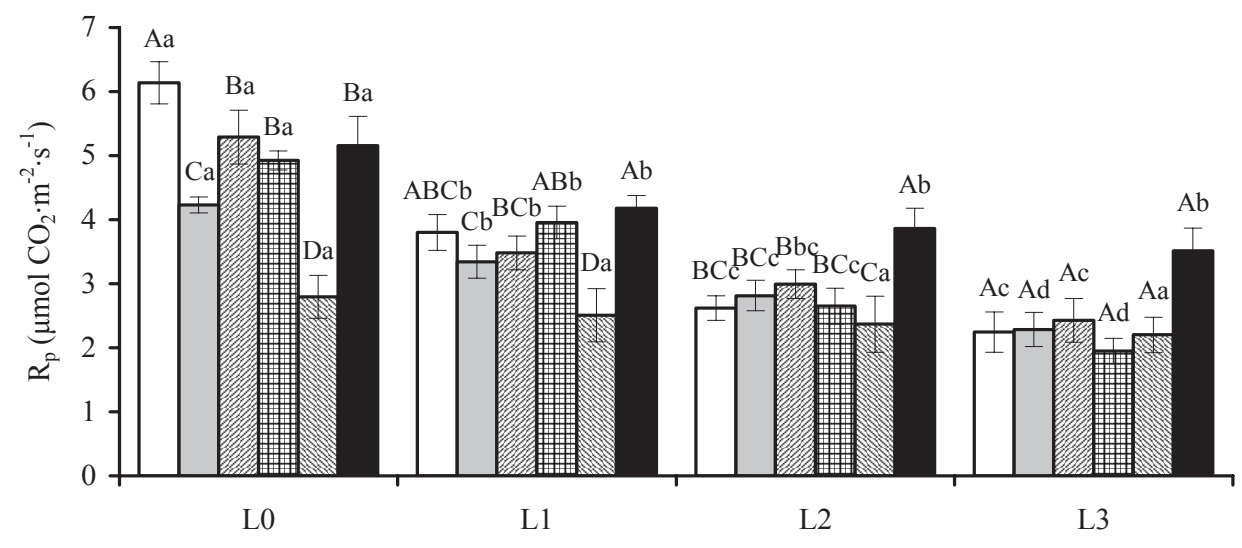

(b)

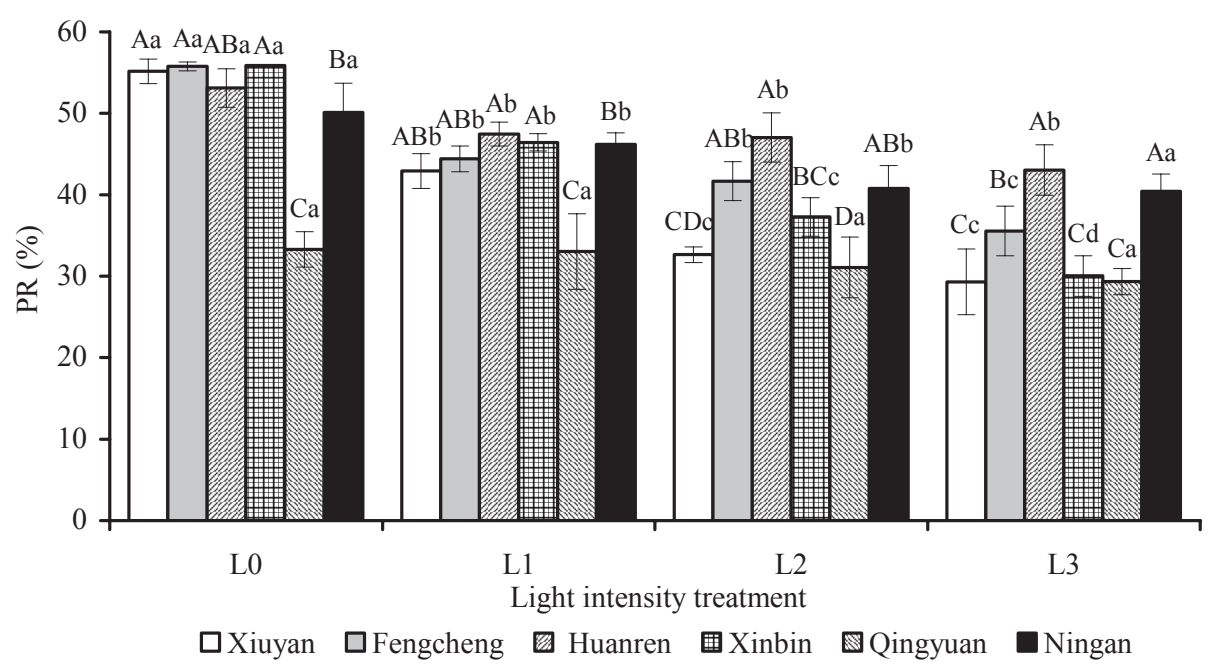

Figure 3 Effect of light intensities on the foliar respiration depletion of Abies holophylla seedlings from different provenances. (a) Rd, (b) Rp, and (c) PR. Same notes as Figure 1

cant differences among different provenances. There were no significant correlation $(P<$ 0.05 ) between the sensitivities of A.holophylla seedlings to changed light intensities and the geological and climatic conditions of $\mathrm{A}$. ho- lophylla provenances (Table 5), but the relationships of sensitivities and annual temperature difference, mean temperature in January and mean annual evaporation of provenance were most closely related. The results showed 
that though the sensitivities of $A$. holophylla seedlings to changed light intensities were not controlled by a single environmental factor. Instead, temperature range and effective precipitation of provenance probably were the main factors which affected phenotypic plasticity of A. holophylla seedlings.

\section{Conclusions}

Light intensities have significant effects on the foliar photosynthetic parameters of $A$. holophylla seedlings from six provenances. As the light intensity dropped, the foliar $\mathrm{CO}_{2}$ assimilation capacity of $A$. holophylla seedlings sharply decreased, and the foliar light utilization capacity significantly increased. The observed photosynthetic physiological changes are crucial to the survival and growth of regenerated seedlings of $A$. holophylla in natural stand. Highly significant differences in the $\mathrm{CO}_{2}$ assimilation capacity, the light utilization capacity, and the respiration depletion of $A$. holophylla seedlings were observed among six provenances under different light intensities. The variations in foliar photosynthetic parameters of A. holophylla seedlings were abundant among different provenances and were mainly controlled by the genetic factors of the provenance itself. The observed significant differences in foliar photosynthesis of A. holophylla seedlings among different provenances were caused by the different sensitivities to changed light intensities. Correlation analysis showed that temperature range and effective precipitation of provenance were probably the main factors that affected phenotypic plasticity of $A$. holophylla seedlings.

\section{Acknowledgments}

This study was supported by the Joint Project of Scientific Research and Postgraduate Education of Key Laboratory for Silviculture and
Conservation of Ministry of Education-the Rationality of Representative Urban Forest Structure in Beijing and the Efficient Technology of Woody Material Process and Utilization, a research program sponsored by Beijing Municipal Commission of Education.

\section{References}

Andrews S.F., Flanagan L.B., Sharp E.J., Cai T., 2012. Variation in water potential, hydraulic characteristics and water source use in montane Douglas-fir and lodgepole pine trees in southwestern Alberta and consequences for seasonal changes in photosynthetic capacity. Tree Physiology 32(2): 146-160.

Aspinwall M.J., King J.S., McKeand S.E., Domec J.C., Whitehead D., 2011. Leaf-level gas-exchange uniformity and photosynthetic capacity among loblolly pine (Pinus taeda L.) genotypes of contrasting inherent genetic variation. Tree Physiology 31(1): 78-91.

Babaei S.F., Jalali S.G., Sohrabi H., Shirvany A., 2014. Growth responses to irradiance regime along an ecological gradient of Quercus castaneifolia seedlings of different provenance. Ecological Research 29(2): 245255.

Carne D.J., 2013. A comparison of carbon sequestration potential and photosynthetic efficiency in evergreen and deciduous oaks growing in contrasting environments in the Southwest UK. Dissertation, University of Plymouth, Plymouth.

Castanha C., Torn M.S., Germino M.J., Weibel B., Kueppers LM., 2013. Conifer seedling recruitment across a gradient from forest to alpine tundra: effects of species, provenance, and site. Plant Ecology \& Diversity 6(3-4): 307-318.

Chong P.F., Su S.P., Gao M., Li Y., Sun Z.C., 2013. Comparative analysis on gas exchange characteristic of four geographical provenances of Nitraria tangutorum. Acta Prataculturae Sinica 22(2): 307-312. (In Chinese).

Dinakar C., Djilianov D., Bartels D., 2012. Photosynthesis in desiccation tolerant plants: energy metabolism and antioxidative stress defense. Plant Science 182: 29-41.

Duan J., Xu C.Y., Jacobs D.F., Ma L.Y., Wei H.X., Jiang L.N., Ren J., 2013. Exponential nutrient loading shortens the cultural period of Larix olgensis seedlings. Scandinavian Journal of Forest Research 28(5): 409-418.

e Silva E.A.B., Hasegawa S.F., Ono K., Sumida A., Uemura S., Hara T., 2012. Differential photosynthetic characteristics between seedlings and saplings of Abies sachalinensis and Picea glehnii, in the field. Ecological Research 27(5): 933-943.

Farquhar G.D., von Caemmerer S., Berry J.A., 1980. A biochemical model of photosynthetic $\mathrm{CO}_{2}$ assimilation in leaves of $\mathrm{C}_{3}$ species. Planta 149(1): 78-90.

Flexas J., Diaz-Espejo A., Gago J., Gallé A., Galmésa J., 
Gulíasa J., Medranoa H., 2014. Photosynthetic limitations in Mediterranean plants: A review. Environmental and Experimental Botany 103: 12-23.

Galmés J., Aranjuelo I., Medrano H., Flexas J., 2013. Variation in Rubisco content and activity under variable climatic factors. Photosynthesis Research 117(1-3): 7390.

Goldblum D., Kennett C., Lisowski A., 2012. Geographical variation in the photosynthesis characteristics of sugar maple (Acer saccharum) lab-and field-grown seedlings. Geographical Bulletin 53(2): 65-78.

Jiang Z.R., Liang X.T., Zhu G., Song Y.P., Cong R.L., Wang S.X., Yang Q.Q., 2008. Sensitivity of three tree species reaction to seasonal variation and its relation to antistress ability. Journal of Northwest Forestry University 23(6): 46-49. (In Chinese)

Jin X., Hu W.L., Kong X.W., Ding G.Q., Ding L., Xu QX., 2008. The effects of shading on the growth of Abies holophylla seedlings. Journal of Liaoning Forestry Science \& Technology (1): 29-34. (In Chinese)

Klein T., Di Matteo G., Rotenberg E., Cohen S., Yakir D., 2013. Differential ecophysiological response of a major Mediterranean pine species across a climatic gradient. Tree Physiology 33(1): 26-36.

Larcher W., 2003. Physiological plant ecology: ecophysiology and stress physiology of functional groups. Springer, Berlin.

Liu L.F., 2012. The Effects of Light on the nutrient absorption and partitioning of Abies holophylla seedlings. Dissertation, Beijing Forestry University, Beijing. (In Chinese)

Mao Q.Z., Watanabe M., Imori M., Kim Y.S., Kita K., Koike T., 2012. Photosynthesis and nitrogen allocation in needles in the sun and shade crowns of hybrid larch saplings: effect of nitrogen application. Photosynthetica 50(3): 422-428.

Nasr Z., Khouja M.L., Aini R., Hammadi A., Manai H., Mimouni B., 2013. Ecophysiological performance of eight Jatropha curcas L. provenances cultivated in Tunisia. Journal of Applied Horticulture 15(2): 90-94.

Okuto J.L., Ouma G., 2010. Provenance variation of photosynthesis of seedlings of java plum (S. cuminii) in Western Kenya. Agriculture \& Biology Journal of North America 1(6): 1260-1263.

Pan L., 2011 Study on dormancy release mechanisms of Abies holophylla Maxim. seed. Dissertation, Beijing Forestry University, Beijing. (In Chinese)

Paquette A., Fontaine B., Berninger F., Dubois K., Lechowicz M.J., Messier C., Posada J.M., 2012. Norway maple displays greater seasonal growth and phenotypic plasticity to light than native sugar maple. Tree Physiology 32(11): 1339-1347.

Pérez-Ramos I.M., Gómez-Aparicio L., Villar R., García L.V., Marañón T., 2010. Seedling growth and morphology of three oak species along field resource gradients and seed mass variation: a seedling age-dependent response. Journal of Vegetation Science 21(3): 419-437.

Reinhardt K., Castanha C., Germino M.J., Kueppers L.M.,
Pereira J., 2011. Ecophysiological variation in two provenances of Pinus flexilis seedlings across an elevation gradient from forest to alpine. Tree Physiology 31(6): 615-625.

Rodríguez-García E., Bravo F., 2013. Plasticity in Pinus pinaster populations of diverse origins: Comparative seedling responses to light and Nitrogen availability. Forest Ecology and Management 307: 196-205.

Shi H.J., Du F., Zhang X.C., 2010. Photosynthetic characteristic of some plant species in the Mu Us Desert. Journal of Northwest Forestry University 25(4): 29-34. (In Chinese)

Song X.L., Yang H.Y., Zeng L.Q., Duan Y.Y., 2009. Study on the shading impact on plant. Northern Horticulture (5): 129-133. (In Chinese)

Soustani F.B., Jalali S.G., Sohrabi H., Shirvany A., 2014. Growth responses to irradiance regime along an ecological gradient of Quercus castaneifolia seedlings of different provenance. Ecological Research 29(2): 245-255.

Sun J.Y., Yang F.J., Pang H.H., Zhang X.K., Zu Y.G., 2007. Effects of shading treatment on photosynthetic response and life cycle form of Taxus chinensis var. mairei. Bulletin of Botanical Research 27(4): 439-444. (In Chinese)

Sunil N., Vanaja M., Kumar V., Abraham B., Chakrabarty S.K., 2013. Variation in physiological traits in Jatropha germplasm from peninsular India. Indian Journal of Plant Physiology 18(2): 151-156.

Wang G.G., Bauerle W.L., Mudder B.T., 2006. Effects of light acclimation on the photosynthesis, growth, and biomass allocation in American chestnut (Castanea dentata) seedlings. Forest Ecology and Management 226(1): 173-180.

Wientjes E., van Amerongen H., Croce R., 2013. Quantum yield of charge separation in photosystem II: functional effect of changes in the antenna size upon light acclimation. Journal of Physical Chemistry B 117(38): 1120011208.

Wyka T.P., Oleksyn J., Żytkowiak R., Karolewski P., Jagodziński A.M., Reich P.B., 2012. Responses of leaf structure and photosynthetic properties to intra-canopy light gradients: a common garden test with four broadleaf deciduous angiosperm and seven evergreen conifer tree species. Oecologia 170(1): 11-24.

Xu C.L., Sun X.M., Zhang S.G., 2012. Comparison in photosynthetic characteristics of Larix kaempferi, L. olgensis and their hybrids. Journal of Beijing Forestry University 34(4): 62-66. (In Chinese).

Yao L., Wang Y., Ma J.F., Liu M.S., 2012. Discussion the effect on Abies holophylla canopy density to growth of natural regeneration seedling. Forestry Prospect and Design (1): 91-92. (In Chinese).

Zhao X.Y., Ma K.F., Zhang M., Bian J.L., Jiao W.Y., Zhang Z.Y., 2011. Comparative analysis of the photosynthetic characteristics of three-year-old Populus tomentosa clones. Forest Research 24(3): 370-378. (In Chinese).

Zhu X.G., Long S.P., Ort D.R., 2010. Improving photosynthetic efficiency for greater yield. Annual Review of Plant Biology 61: 235-261. 